\section{DENTAL STUDENT WRITES A MESSAGE FROM CORONA FOR KIDS}

Charity Tedder, 25, a final year dental student from Peninsula School of Dentistry, has written an e-book called $A$ Message from Corona to help inform and reassure children during the COVID-19 pandemic.

The book, illustrated by Kent-based artist Leighton Noyes, explains vividly and engagingly how the virus has travelled around the world, and why hand-washing, social distancing and lockdown are so vital. It can be read to children as young as age three to four or self-read by ages seven to eight and above. There are also activity pages for children to help keep them engaged.

Charity's father, leading virologist Richard Tedder, based at Imperial, who is at the forefront of research into the coronavirus, has endorsed the book and helped to ensure that its content is factually correct. A Message from Corona has been passed round Parliament by Charity's local MP Adam Holloway and a number of organisations including Public Health England, Barclays, universities and schools.

Charity told the $B D J$ : 'We have received great feedback about the book. With the success we have had so far, we would love to

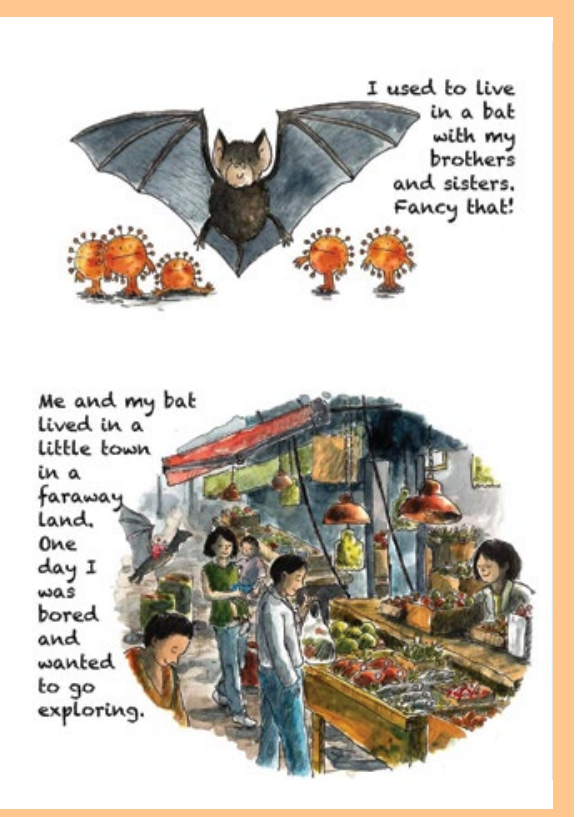

take [it] further and are looking at getting it published. So far it has been shared over 1,000 times and has been greatly received'

The book and the activity pages can be viewed via the following link: https://www. gofundme.com/f/a-message-from-corona.

Funds raised from the e-book will be put towards fighting the COVID-19 crisis.

\title{
DENTIST DESIGNS CHILD-FRIENDLY PPE POSTER
}

Ajit Tanday, Clinical lecturer, specialist and post ccst at Birmingham Dental Hospital and member of the British Society of Paediatric Dentistry (BSPD), developed this poster to teach children not to be afraid of professionals wearing full PPE gear. Ajit was assisted by relative Amanda Sharma who wrote the poem and Dr Pippa who drew the illustrations.

Ajit has also shared the poem on Twitter for everyone to use and adapt. @tanday 83
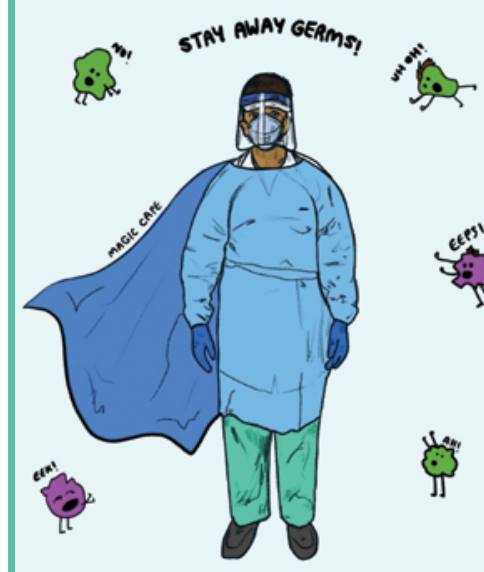

If you go to the dentist today, be sure of a big surprise.

For you will see a superhero before your very eyes.

They cannot fly or lift a car but the special thing they do

Is wear some magic clothes and masks to help protect all of you.

A big blue Cape, some rubber gloves and masks up to their eyes. Don't be afraid of what you see, remember this is their disguise The germs don't like the magic clothes, so it helps keeps them away

So you don't get sick or poorly and you can still have fun and play.

So now you know the secret of the special thing they do. Superheroes at the dentist and they have helped look after you.

By: Amanda Sharma and Ajit Tanday

BSPI issues

\section{plea to}

\section{parents aluring lockalown}

The British Society of Paediatric Dentistry (BSPD) is urging parents to make sure their young children do not take unnecessary risks during the COVID-19 pandemic.

Accidents can happen

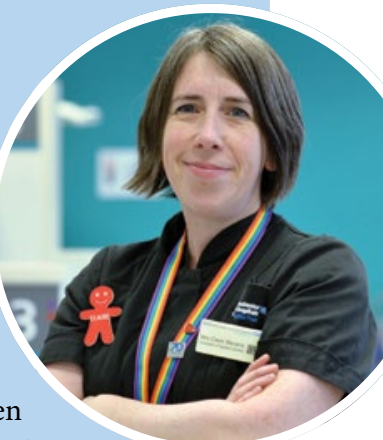
at any time and frequently do in childhood. But while some are inevitable, there are accidents that can and should be avoided, especially now.

Spokeswoman Claire Stevens CBE, a Consultant in Paediatric Dentistry, said: 'I would like to put in a plea to parents and carers to limit play which could potentially lead to a fall or a crash resulting in damage to teeth. We are still seeing cases of dental trauma which is worrying.'

She explained that normally, when a child damages their permanent teeth, the dentist refers the child to an urgent dental care clinic or if they require specialist treatment, to a dental hospital. But dental practices are closed and hospitals are now only providing emergency care. Access to general anaesthetic is limited as medical colleagues must use life-saving equipment to care for COVID positive patients.

'Getting fresh air and exercise is important but it's also important to assess the potential risk of each activity. Many of the admissions we are seeing are for accidents that could have been prevented,' said Dr Stevens.

'When children are young and still not confident riding a bike or a scooter, a crash could easily damage a tooth. The roots of permanent teeth are not well established when they first come through and this would be considered an unfortunate accident at the best of times. Now, in the worst of times, even greater care should be taken to avoid unnecessary risks.

'My advice is to never allow more than one child at a time on a trampoline - they can so easily crash into each other if they go on the trampoline at the same time.' 